\section{Frustration Tolerance}

Dawn E. Bouman

Neuropsychology and Medical Psychology, Department of Neurology and Rehabilitation Medicine, University of Cincinnati, Cincinnati, $\mathrm{OH}$, USA

\section{Synonyms}

Short-fuse syndrome

\section{Definition}

Frustration tolerance is the ability to withstand obstacles and stressful situations. Decreased frustration tolerance is a common behavior problem of people who have brain injuries. Low frustration tolerance can be a direct result of brain damage as well as a secondary reaction to the lifestyle changes and losses which might accompany a brain injury. Typically conceptualized as an executive functioning impairment, low frustration tolerance is viewed as a problem with selfregulation. Behavioral manifestations include irritability, aggression, lability, and refusal to participate. As with other behavior problems, difficulties with frustration tolerance are often exacerbated by fatigue.

\section{Cross-References}

Agitation

- Catastrophic Reaction

- De-escalation

- Emotional Lability

- Executive Functioning

- Irritability

- Self-Regulation

\section{References and Readings}

Callahan, C. D. (2009). The assessment and rehabilitation of executive function disorders. In B. Johnstone \& H. H. Stonnington (Eds.), Rehabilitation of neuropsychological disorders (2nd ed., pp. 75-106). Philadelphia: Psychology Press, Taylor and Francis Group.

Lezak, M. D., Howieson, D. B., Bigler, E.D. \& Tranel, D. (2012). Neuropsychological assessment (5th ed., pp. 39, 210, 705). New York: Oxford University Press. 